\title{
Historein
}

Vol $2(2000)$

Heterodoxies: Constructions of Identities and Otherness in Medieval and Early Modern Europe

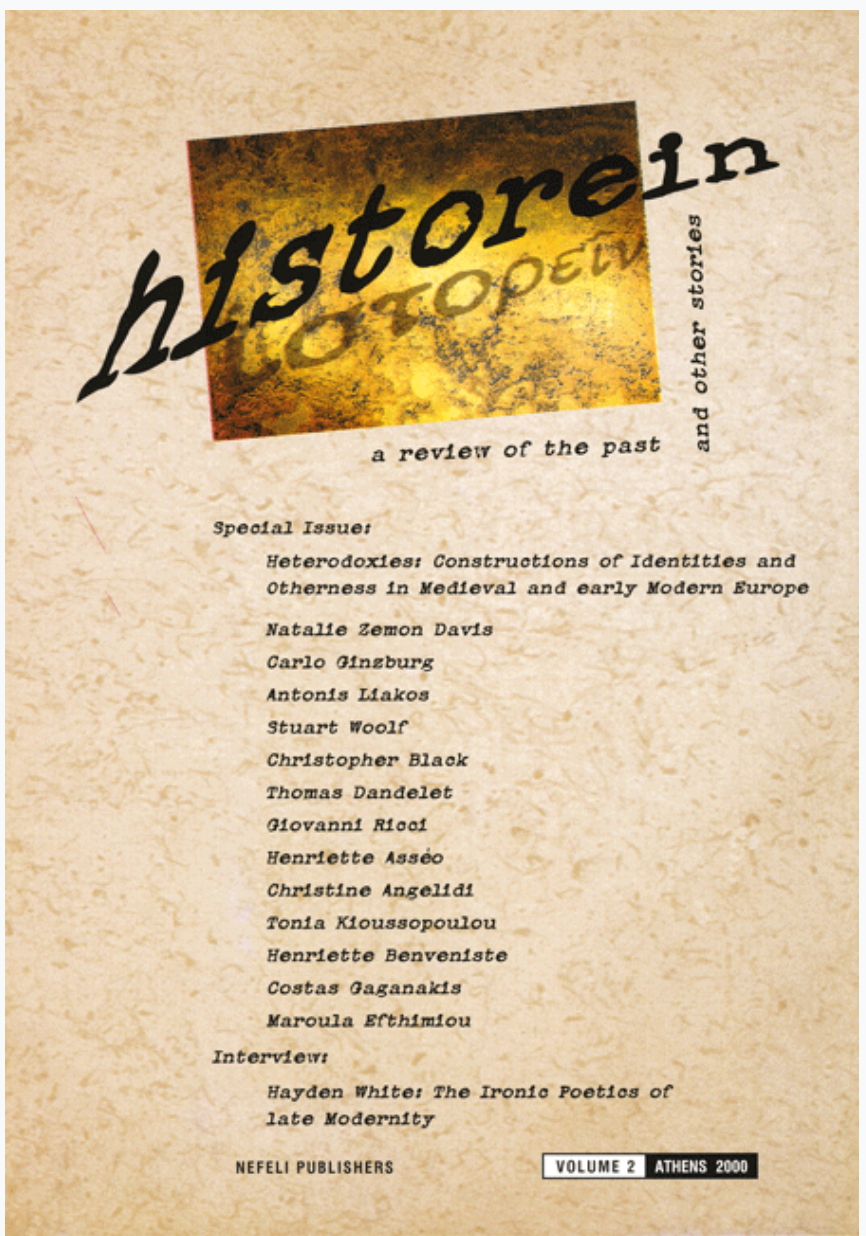

\section{The Transformation of Historical Writing from Syntagmatic to Paradigmatic Syntax}

Antonis Liakos

doi: $10.12681 /$ historein.111

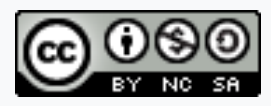

This work is licensed under a Creative Commons Attribution-NonCommercialShareAlike 4.0.

\section{To cite this article:}

Liakos, A. (2001). The Transformation of Historical Writing from Syntagmatic to Paradigmatic Syntax. Historein, 2, 47-54. https://doi.org/10.12681/historein.111 


\section{The}

\section{Transformation}

of Historical

\section{Writing}

from

\section{Syntagmatic}

\section{to}

\section{Paradigmatic}

\section{Syntax}

\section{Antonis Liakos}

The work of Natalie Zemon Davis and Carlo Ginzburg is central to the new cultural history. In this paper I will explore the ways in which these two authors have contributed to the transformation of contemporary historical writing, and how their work embodies a moment in the transition from a "syntagmatic" to "paradigmatic" syntax of historical writing.

As opposed to semantics, the term syntax refers, here, to rules of narrative composition with regard to the relation between the object of historical writing and the historical text. What is the difference between the syntagmatic and the paradigmatic syntax of historical writing ?' $^{\text {In }}$ syntagmatic writing historians follow a preexisting time order proceeding from earlier to later events. Time order is pre-existing, because events have been largely pre-selected by social practices. For example, political history usually refers to the facts that we recognize as political events because they belong to a structure already defined as politics: governmental and parliamentary acts, elections, diplomatic activities, etc. The fields of inquiry of economic, religious or art history had already been socially defined as economic, religious or art facts, before the historians intervened and transformed them into their objects of study. Thus, socio-cultural structure pre-selects the material that the historian is forced to reconstruct and represent in a given time order.

On the other hand, in paradigmatic syntax historians use events not according to their temporal sequence, but according to the structure of the particular problem with which they are willing to deal. Therefore, the selection and use of the historical data is disconnected from their temporal order. Historical facts are 
not pre-selected and deposited in social structure as such. Thus, the intervention of the historian in selecting them is not constrained by a pre-existing ordering of events in social categories or in institutions of meanings.

History writing, as intellectual construction and re-elaboration of the past is not a unilateral practice. It exists in a dialogic form between the historian's intellectual formation and the preexisting social construction of reality. A dialogic form is an exchange of messages between the "historicizing" present and the "historicized" past. The system of historical writing is not independent of what it represents, being in close relation with it. The visibilia of the past are organized into texts, archives, libraries, museums etc. All of these are vehicles for meanings that travel from the past to the present. In this course, successive emitters and receivers of historical information are generated as authors and readers in interchangeable places. According to Paul Ricoeur, the past in se has no narrative structure; ${ }^{2}$ but the past is given a narrative structure. This structure is not given by the single author, but by the way this past was conceived by contemporaries and the successive generations of observers and historians. This given narrative structure of the past is the "reality" which historians refer to, or try to unravel. So, the difference between the syntagmatic and the paradigmatic syntax is that the latter decomposes the imposed narrativity of the past. In this way, the "historicizing" present is more empowered in regard to the "historicized" past, but not entirely arbitrary. This "empowerment" consists in tracing, into the past, meanings that are neither mediated by the intermediate interpretative framework that is applied to the past nor even compatible with it.

Another way to explain the difference between the two syntaxes is to use Clifford Geertz's distinction between the "locus" and the "object" of the study in social anthropology. Syntagmatic syntax of historical writing occurs when the locus of the study coincides with the object of the study. Such a coincidence was the case in the great historical narratives produced under the influence of historicism. The locus of historical investigation and writing was identical with the object of historical interest. Historians sought to reconstruct the past of concrete entities such as states and nations, institutions, ideas or personalities. Historical narratives were coherent, based on a representational symmetry between evidence, facts and truth. On the other hand, in paradigmatic syntax the locus of the study is dissociated from the object of the study. In this case the object of study refers to a theoretical dialogue, on various levels of abstraction. As Clifford Geertz has noted,

You can study different things in different places, and some things... you can best study in confined localities. But that doesn't make the place what it is you are studying. In the remote provinces of Morocco and Indonesia I have wrestled with the same questions... and with about the same conclusiveness... Anthropologists don't study villages, they study in villages. ${ }^{3}$

According to this argument, historians, using paradigmatic syntax, do not study cases; they 


\section{study in cases.}

An example of where this difference in syntax is visible could come from the comparison between two books: J.L. and Barbara Hammond, The Town Laborer, 1760-1832 (1920), and E.P.Thompson, The Making of the English Working Class (1963). Both books use as their locus the English working class at the end of eighteenth and the beginning of the nineteenth century. However, in Hammonds' book the locus of their study is the same as their objects; they seek to provide facts and interpretations for understanding the conditions of the British working people during the industrial revolution. On the other hand, Thompson focuses on a theoretical debate: the definition of the social class, the relation of social being to social consciousness and the connection among experience, culture and ideology. Three well-known examples of paradigmatic syntax are the books by Carlo Ginzburg, Il formaggio e i vermi (1976); Natalie Zemon Davis, The Return of Martin Guerre (1983); and Robert Darton, The Great Cat Massacre (1984). These books and the influence of interpretative anthropology, in particular of Clifford Geertz's "thick description" [Cockfights in Bali (1973)], were important in this broad transformation of historical writing. ${ }^{4}$

Sub speciae semioticae, in paradigmatic syntax, the standards of evidence are subjected to a synecdochic conception of metaphor. Instead of evidence representing events, the events are used as evidence in a theoretical construction. This transition from the syntagmatic to the paradigmatic syntax of history writing is not abrupt, because forms of the latter exist in the former. Metonymy is often used in narratives ordered along a linear scale of time, mainly in social and cultural history. Two great historical masterpieces of cultural history, Jacob Burkhard, The Civilization of the Renaissance in Italy (1860), and Norbert Elias, The Civilizing Process (1939) are constructed in a paradigmatic manner, inside a syntagmatic conception of writing.

The French school of Annales constitutes a transitional moment from the one to the other syntax. The Annales school dropped out the classical narration that followed the flux of time, split time into temporal duration according to the locus of history, and introduced the "histoire-probleme." 5 In this approach, a problem is constituted by the comparison between theoretical premises and empirical data. This course of starting from a theoretical debate, plunging into empirical data, and returning to the theoretical debate constitutes the general pattern within which paradigmatic history is inscribed.

On the other hand, in a similar way, syntagmatic syntax remains a subordinate element in the works of paradigmatic syntax. This is what has been described as the return of narrative versus structural history. ${ }^{6}$ Take for example the two works by Davis, The Return of Martin Guerre (1983) and Women on the Margins (1995). Both works are biographies of a highly syntagmatic construction. The first concerns the life of a peasant in sixteenth century France and the second narrates the life of three very different women in the seventeenth century. Both had been written in 
syntagmatic syntax, but this syntax is subordinate to a paradigmatic syntax. What does this mean? It is difficult to imagine that in a syntagmatic history of early modern Europe there would be any mention of the life of Martin Guerre, or Glikl from Hamburg and Marie d' Incarnation and Maria Sibylla Merian, all of Davis' heroes and heroines. It is the paradigmaticity of these stories that matters. This particular paradigmaticity addresses the problems, in the form of "historyproblem", of justice and narration, as well as of gender history and gender-conditioned writing. The case of Ginzburg's Menochio is similar. It is difficult to imagine that the history of a Friulan miller could find a place in a syntagmatic history of the Reformation and Counter-Reformation in Italy. It is the relationship between high and low culture that matters here. The problems arising from a theoretical debate constitute the starting point of these stories. Martin Guerre, the three women and the Friulan miller are the loci of these stories, although the object of these stories, i.e. the investigation and argumentation, is different and concerns another level of contemporary theoretical debate. The specificity of these approaches is that they not only dismantle the existing time ordering of the past, but that in order to address theoretical problems, they introduce a narrative form quite unusual in the social sciences.

This transition from syntagmatic to paradigmatic syntax of history is parallel and homologous to the use of time in fiction and literature, from the realistic fiction of the nineteenth century, which was marked by the detailed description of persons and situations, to the modernist novel writing (Proust, Joyce, Virginia Woolf) which followed. As Siegfried Kracauer has written,

The pioneers of the modern novel no longer care to render biographical developments and chronological sequences after the manner of the older novel; on the contrary, they resolutely decompose (fictitious) continuity over time. In other words, they seek, and find, reality in atom-like happenings, each being thought of as a center of tremendous energies (...) The "order of life," ungiven them, may or may not exist. In fact, they rather doubt whether the small random units in which life, really tangible life, materializes are meaningfully interconnected, so that in the end the shadow contours of a whole will delineate themselves at the horizon. ${ }^{7}$

Kracauer quotes from Erich Auerbach that,

those modern writers who prefer the exploitation of random everyday events, contained within a few hours and days, to the complete and chronological representation of a total exterior continuum, they too (more or less consciously) are guided by the consideration that it is a hopeless venture to try to be really complete within the total exterior continuum and yet to make what is essential stand out. Then too they hesitate to impose upon life, which is their subject, an order which it does not possess in itself. ${ }^{8}$

In this way, the highly syntagmatic order of realist narrative was transformed into the paradigmatic syntax of the modernist novel. This reversal in literature was not a consequence of 
changes in style only, but a whole project of re-ordering the relationship between private experience and public experience, between subjectivity and history. While the aim of the realistic novel was to present the impact of History (the historical experience) upon the individual, the modernist novel seeks to liberate subjective experience from history. There is a distinctive phrase in Joyce's Ulysses, "History is the nightmare from which I am trying to awake," which express the personal frustration from history. As the individual sense of history is often in silent contrast with the narration of history, so, the individual's "organic time" does not coincide with historical time. This discontinuity between historical and the personal time arises from the incompatibility between personal experience and historical description of this experience. ${ }^{9}$ This description is constructed according to values, master narratives and general ideas like national or social emancipation, progress, modernization, etc. In the public imagination, History (essentialized with capital $\mathrm{H}$ ), is not far from the conception of history as progress, as national fate, as the laws of social evolution, as the rise of Western civilization, as the imposition of general ideas to society. The paradigmatic writing of history rises up against these conceptions of history as well as against generalizations imposed by the social sciences and especially modernization theory. New cultural history for instance could be read as a critique of the high/low culture dichotomy, or the strict structuring of society in distinct layers of economy, society and culture. Against these generalizing trends, transformed by analytical tools into cultural essences, stood men and women like Menochio and Martin Guerre, like Glikl from Hamburg and Marie d' Incarnation and Maria Sibylla Merian. Their identities derived from a self-making action which not only does not confirm the general trends in history; on the contrary, it reveals its limits.

According to the editors of a volume dedicated to Natalie Zemon Davis, "(she) rejects the traditional conceptualization of the early modern period that finds its unity in the teleological notion of an age of transition." She reveals the "uneven and discontinuous changes welling up from within a patchwork of social, spiritual, and cultural realities." ${ }^{10}$ In Ginzburg's case, paradigmatic history is the trace-finding, the process of opening ruptures on the surface in order to discern hidden and forgotten realities. This method has been described as the "evidential knowledge" against the Galilean method used in the social sciences. This is the path of Sherlock Holmes, Morelli, and Freud in his essay "Spie: Radici di un paradigma indiziario."

In this context, we could assess the history of "otherness". Otherness is often conceived as the other way to explore normality, to confirm social standards by way of their boundaries, or of their margins. But to explore otherness and margins is to explore the subjectivity of men and women who don't enter in the great historical mainstream. This exploration needs to see people well beyond these historical courses. Otherness is an object in se.

The Historian: I asked what advantages you had by being on the margins. The first person: Margins are where I read comments in my Yiddish books. The second person: In my Christian books. The third person: River margins are the dwelling place of frogs. The Historian: You found things on margins. 
(From the preface of Natalie Zemon Davis in Women on the Margins)

One could argue that there is a convergence of approaches in the last quarter of the twentieth century toward the specific, the personal, the subjective as well as the re-evaluation of individual agency. Oral history, cultural anthropology, feminism and gender studies contributed to this drive of intellectual interest. In these approaches, subjects are not simply vehicles of meanings; they also have an active role in imposing meanings, especially in periods of uncertainty and conflict over meanings. That is why the tales that are often employed take the form of social drama. There is a preference for trials and judicial cases, as in Davis's book about "Pardon tales," or for Inquisition trials as in the works of Ginzburg. Social drama is a form of narration that not only includes historical information, but also "a genre of cultural performance," a dynamic interchange of positions, significance and intellectual categories. ${ }^{11}$ To a certain degree, the historian takes part in this performance, like Davis herself in the preface to her Women in the Margins, or like Ginzburg in his The Inquisitor as Anthropologist or II giudice e lo storico.

There is a statement in Aristotle's "The Poetics", that poetry is superior to history, because poetry appreciates the universal, although history appreciates the particular. This statement reads as follows: "Poetry is more philosophical and more important than history. Because poetry is speaking for the whole. On the other hand, history describes the part (the particular)." interpret this statement, the first problems to solve are which kind of history Aristotle is referring to; who were the historians he was thinking about; which histories he had in mind. It is difficult to imagine that he was referring to Thucidides. The main feature of his writing is to proceed from the events of the civil war to the pathology of Democracy, and at the same time, to a theory of the civil war, and the war as human conflict. That is from the particular to the whole.

This juxtaposition, in its modern version, could be read as the relationship between history and theory. The encounter between the search for rationality (philosophy of history) and the search for curiosities (antiquarians), as two distinctive ways of knowledge, gave birth to the historiography of the Enlightenment. ${ }^{13}$ History and philosophy were separated anew in the nineteenth century, and historicism was only possible through the distinction of history from "theory." A new encounter with philosophy (not anymore as ontology but as theory of knowledge) was possible in the second half of this century in the context of the fusion of disciplines (anthropology, literary theory, social theory), interdisciplinarity, and transdisciplinarity. Paradigmatic history seems to confirm the Aristotelian consideration that history appreciates the particular. Although it is not the universal but the specific, i.e. the historicity and the local, that paradigmatic history has been seeking, this kind of historical syntax has however opened up possibilities for communication among historians of various specialization and orientations, working on a great variety of topics, scattered over place and time. It has also opened channels of communication among various disciplinary fields and resulted in a proliferation of loci of studies. Though retaining a unified context of theoretical debate, through this transition from syntagmatic to paradigmatic syntax of historical writing, the 
whole plane of academic historical communication has changed in the last quarter of the twentieth century. ${ }^{14}$ This paradox of a type of historical writing that seeks the specific and at the same time results in the opening of historical communication over shared theoretical debates, raises an old question that concerns the cognitive limits of history. So, Aristotle's question could be asked again today: Does history still appreciate the particular? Or rather, how can local knowledge be transmissible? How could communication among historians be possible? Is the historian's universe homogeneous? And what kind of homogeneity constitutes the historian's universe? Why is communication among historians investigating such diverse cases and seeking the particular even possible?

We know that historicism, i.e. seeking the particular vs the Enlightenment "universal", presupposed a strong sense of the researcher's universe as organic and rational. This has been the main object of all social science including marxism. This universe is present in social anthropology as the structure of mind in Levi-Stauss, as the geohistorical time of Braudel, as the rhetorical strategies of Hayden White, or as the textual universe of literary theory and the "linguistic turn." This is the order in which syntagmatic syntax could be possible. But what is the order in which paradigmatic history has been based? In other words: Does a unique conceptual framework grounding historical paradigmaticity exist? ${ }^{15}$

This framework can not be traced to a unified real or symbolic world to which history refers. It could, however, be described in terms of making history. Historicizing should be conceived as a form of knowledge production. The framework represents the dialogic form of history in its double dimension: dialogue between contemporaries and dialogue between the present and the past. This is a strange dialogue combining the illusion of monoglossia with the dominance of heteroglossia. Natalie Zemon Davis's preface in her Women on the Margins, where she is dialogizing with her three women from the past, is an exemplary form of this double dialogue, which in Bakhtinian terms, is the typical epistemological mode of a world dominated by heteroglossia. ${ }^{16}$ And, sub speciae semioticae, the form of a dialogue is not syntagmatic, it is necessarily paradigmatic. 
${ }^{1}$ For the meaning of the terms synatagmatic/paradigmatic: A.Greimas, J. Courtes, Semiotics and Language, Bloomington: Indiana UP, 1979, 327-328, 224-225.

${ }^{2}$ Paul Ricoeur, Time and Narrative, The University of Chicago Press, 1983, vol.1, 56

${ }^{3}$ Clifford Geertz, The Interpretation of Cultures, New York: Basic Books, 1973, 22-25

${ }^{4}$ William H. Sewell "Geertz, Cultural Systems and History: From Synchrony to Transformation" in Sherry B. Ortner, The fate of "Culture". Geertz and Beyond, University of California Press, 1999, 35-55

${ }^{5}$ Guy Massicotte, L'histoire probleme. La methode de Lucien Febvre, Paris: Edisem, 1981

${ }^{6}$ Lawrence Stone, "The revival of Narrative", Past and Present, 85 (1979), 3-24

${ }^{7}$ Siegfried Kracauer, History. The Last Things Before the Last, Princeton: Markus Wiener Publishers, 1995, 182

${ }^{8}$ Erich Auerbach, Mimesis, The Representation of Reality in Western Literature, Princeton University Press, 1953, 548

${ }^{9}$ Martin Davies, "Orpheus or Clio? Reflections on the Use of History", Journal of European Studies, 17 (1987) $179-213$.

${ }^{10}$ Barbara B. Diefendorf and Carla Hesse (ed.) Culture and Identity in Early Modern Europe (1500-1800), Essays in Honor of Natalie Zemon Davis, University of Michigan Press, 1996, 14

${ }^{11}$ Sarah Masa, "Stories in History", American Historical Review, 101,5 (1966)

${ }^{12}$ Арıбтот்́

${ }^{13}$ Arnaldo Momigliano, Studies in Historiography, London, 1969

${ }^{14}$ Georg Iggers, Historiography in the Twentieth Century. From Scientific Objectivity to the Postmodern Challenge, Haniver and London: Weleyan University Press, 1997; Victoria Bonnell and Lynn Hunt, (eds) Beyond the Cultural Turn, University of California Press, 1999, 1-34

${ }^{15}$ Aletta Biersack, "Local Knowledge, Local History: Geertz and Beyond", in Lynn Hunt (ed.), The New Cultural History, Berkeley: University of California Press, 1993, 72-96

${ }^{16}$ M.M. Bakhtin, The Dialogic Imagination, Austin: University of Texas Press, 1981 